\title{
Assessing Effectiveness of Multipurpose Voucher Scheme to Enhance Contraceptive Choices, Equity, and Child Immunization Coverage: Results of an Interventional Study from Pakistan
}

This article was published in the following Dove Press journal:

Journal of Multidisciplinary Healthcare

\author{
Moazzam Ali iD ' \\ Syed Khurram Azmat $\mathbb{D}^{2}$ \\ Hasan Bin Hamza ${ }^{3}$ \\ Md Mizanur Rahman (iD ${ }^{4}$ \\ 'Department of Sexual and Reproductive \\ Health and Research, World Health \\ Organization, Geneva, Switzerland; \\ ${ }^{2}$ Department of Technical Services, \\ Greenstar Social Marketing, Karachi, \\ Pakistan; ${ }^{3}$ Health Policy, System \\ Strengthening and Information Analysis \\ Unit, Ministry of National Health \\ Services, Regulations and Coordination, \\ Islamabad, Pakistan; ${ }^{4}$ Department of \\ Global Health Policy, School of \\ International Health, The University of \\ Tokyo, Tokyo, Japan
}

Background: Pakistan has a high total fertility and unmet contraceptive need and is the fifth most populous country. This research aims to assess the effectiveness of a subsidized, multipurpose voucher intervention to enhance the client-provider interaction for improved contraceptive counseling resulting in a potential increase in the modern methods uptake, continued use, and its impact on equity through better targeting, while increasing uptake of postnatal care and child immunization among women from the lowest two wealth quintiles in rural and urban communities of Punjab province, Pakistan.

Methods: We used a quasi-experimental design with pre- and post-phases in intervention and control sites in Punjab province (August 2012-March 2015). To detect a 20\% increase in modern contraceptive prevalence rate compared to baseline, 1276 women were enrolled in each arm. Difference-in-differences (DID) estimates are reported for key variables. Absolute and relative index of inequality including concentration curves and concentration index are used to describe the magnitude and extent of equity.

Results: With no net increase in modern contraception use, the intervention area, however, reported a low modern method discontinuation rate. Vaccination rates for BCG increased significantly by $14 \%$, and $5 \%$ each for DPT, HBV, and measles. Concentration index and slope index of inequalities for first-time use of modern contraceptives, knowledge of contraceptives, receiving ANC, and delivery at health facilities were negative, indicating that the use of these services was more concentrated among the disadvantaged in intervention areas than the wealthy counterparts.

Conclusion: This Greenstar-led multiple voucher model did not significantly increase modern contraceptive use in the intervention study area but positively impacted equity. The integrated approach combining contraception with child immunization led to an increase in immunization coverage. It will be important for public policy decision-makers to assess the usefulness of this approach, as a long-term provision of free contraceptive services may lead to dependency in targeted communities.

Keywords: vouchers, contraceptives, family planning, equity, immunization, Pakistan

\section{Plain Language Summary}

Greenstar and Population Services International used low-priced vouchers for multiple purposes as a possible solution to enhance the client-provider relationship. The vouchers combined family planning (FP) counseling and services along with child immunization, especially for mothers bringing their newborns for check-up and routine vaccination. In
Department of Sexual and Reproductive Health and Research, World Health Organization, Avenue Appia 20, Geneva

$27 \mathrm{CH}-\mathrm{I} 2 \mathrm{II}$, Switzerland

Tel +4l (22) 79l 3442

Email alimoa@who.int 
that sense this intervention had the advantage of addressing multiple client needs related to maternal and child health at the same time. The study had an intervention and a control arm. Questions were asked from the family planning clients at baseline and end line, selected at their residence via household sampling, about their knowledge and current practices of family planning such as current preferred method and why they use it over other choices available. The results of the study show that multi-purpose vouchers were not largely successful in increasing modern contraceptive use in study areas. We did, however, find that voucher use was more common among poor women, and their knowledge and the current overall use of family planning methods had increased considerably. Another important finding was that about half of the total women in the intervention areas were more likely to take up a modern family planning method for the first time compared to women in non-intervention areas. Vaccination coverage also increased in the intervention area. Low priced vouchers when used for family planning counseling have the potential to increase child immunization and first-time use of modern family planning methods in the underserved and vulnerable segments of the population.

\section{Introduction}

Unintended pregnancies, resulting from an unmet need for contraception, threaten the lives and wellbeing of women and their families globally. ${ }^{1}$ Contraceptives are one of the most cost-effective investments a country can make for its future. ${ }^{2}$ Contraception offers a range of potential benefits that encompass economic development, maternal and child health, education, and women's empowerment. In some developing countries, increased contraceptive use has already cut the annual number of maternal deaths by $40 \%$ over the past 20 years, and reduced the maternal mortality ratio (the number of maternal deaths per 100 000 live births) by about $26 \%$ in little more than a decade. ${ }^{3}$

According to 2017 estimates, 214 million women of reproductive age in developing regions have an unmet need for family planning. ${ }^{4}$ It is highest among the most vulnerable in society: adolescents, the poor, those living in rural areas and urban slums, people living with HIV, and internally displaced people. ${ }^{1}$

To accelerate progress towards attainment of international development goals and targets in sexual and reproductive health, and to contribute to meeting unmet needs for contraceptive information and services, contraceptive services should be available, accessible, acceptable, and of good quality, and provided without discrimination. ${ }^{1}$ Inequitable access in family planning services continues to be a challenge. ${ }^{4-6}$ The World Health Organization identifies research on intervention mechanisms that helps promote contraceptives uptake as a priority. ${ }^{7,8}$

Vouchers have emerged as an effective strategy to combat inequities in increasing access to and use of modern contraceptive services and have also been used broadly in sexual and reproductive health interventions, ${ }^{9,10}$ especially for special populations including the poor, youth, and postpartum women. $^{11-13}$

Pakistan has a high population growth rate and, as per the latest 2017 Census, Pakistan's current population is 207.8 million. By 2030, it is expected to rise to a projected 350 million. The PDHS 2017-18 indicates that the current fertility rate in Pakistan is 3.6 children per woman, and that the modern Contraceptive Prevalence Rate (mCPR) is around $25 \%$ and the unmet need for Family Planning is $17 \%$. $^{14}$

In Pakistan, some studies were conducted using a combination of social franchising and vouchers in maternal health and family planning with mixed results. ${ }^{15-17}$ This study aims to assess the effectiveness of a multipurpose voucher approach vs the control in increasing the uptake of modern contraceptives, postnatal care, and child immunization; and understanding its impact on equity by studying women from the lowest two wealth quintiles in underserved communities of the intervention district (Faisalabad) and control district (Toba Tek Singh) in Punjab, Pakistan.

\section{Methods}

This was a quasi-experimental study with pre, and post phases implemented across intervention (Faisalabad) and control arm (Toba Tek Singh) districts. These districts were selected based on comparable socio-demographic and health indicators (Table 1). ${ }^{18}$ For the pre-intervention phase an independent baseline survey was conducted in August 2012 to provide information on the prevalence of key project indicators in the intervention and control districts. ${ }^{19,20}$ The intervention ended in March 2015. In the post-intervention phase, we conducted an independent end line cross-sectional household survey in the intervention and control districts in March 2015. (Table 2)

\section{Study Interventions}

Based on the study design, ${ }^{20}$ Greenstar Social Marketing (GSM)/Population Services International (PSI) project employed a low-priced multi-purpose voucher scheme in the intervention areas, assuming that it is the lack of awareness due to poor counseling (not affordability) 
Table I Comparability of Intervention and Control Districts

\begin{tabular}{|c|c|c|}
\hline Profile & $\begin{array}{l}\text { Faisalabad } \\
\text { (Intervention) }\end{array}$ & $\begin{array}{l}\text { Toba Tek } \\
\text { Singh } \\
\text { (Control) }\end{array}$ \\
\hline District area & $5856 \mathrm{~km}^{2}$ & $3252 \mathrm{~km}^{2}$ \\
\hline District population & $5.43 \mathrm{~m}$ & $1.39 \mathrm{~m}$ \\
\hline Literacy rate & $51.9 \%$ & $50.5 \%$ \\
\hline $\begin{array}{l}\% \text { of household population using } \\
\text { improved sources of drinking } \\
\text { water and using sanitary means of } \\
\text { excreta disposal }\end{array}$ & $74 \%$ & $78.6 \%$ \\
\hline $\begin{array}{l}\text { Currently married women aged } \\
15-19\end{array}$ & $2.4 \%$ & $3.7 \%$ \\
\hline \multicolumn{3}{|l|}{ CPR } \\
\hline $\begin{array}{l}\% \text { of any contraceptive method } \\
\text { use among married women }\end{array}$ & $44.1 \%$ & $36.5 \%$ \\
\hline $\begin{array}{l}\% \text { of any modern method use } \\
\text { among married women }\end{array}$ & $33.3 \%$ & $25.3 \%$ \\
\hline $\begin{array}{l}\% \text { of any traditional method } \\
\text { use among married women }\end{array}$ & $10.7 \%$ & $11.2 \%$ \\
\hline
\end{tabular}

leading to, no- or low-utilization of modern contraceptive services. This intervention focused to enhance the clientprovider interaction with improved FP counseling. The salient features of the intervention were the following:

- The GSM/PSI intervention comprised a booklet of vouchers that pre-paid 13 visits to service providers over an 18-month period.

- The vouchers catered for two postnatal care (PNC) visits (services and counseling), five child immunizations (services and counselling) and six family planning visits (only FP counseling included, the client paid for the preferred product).

- The cost of the complete voucher booklet was 50 Pakistan rupees (US\$1=98.7 Pakistan rupees).

- The vouchers were distributed through service providers and distributing agencies to eligible poor women (the service providers and the field workers of the distributing agencies screened potential clients asking questions on modern contraceptive access, use ever/current and availability).

- The providers were trained on inter-personal communication and behavior change communication to provide contraceptives and maternal/child health awareness to the potential clients.

- Poverty was defined as those women who belonged to the poorest two quintiles using a poverty assessment tool.

It was assumed that the multi-purpose voucher approach, if effective, could help in enhancing more interactions between clients and providers leading to increased contraceptive service uptake as well as simultaneously achieving other maternal and child health goals, especially child immunization.

\section{Study Participants}

Clients for vouchers, ie, married women of reproductive age (MWRA) aged between 18-49 years from the lowest two wealth quintiles (including, but not limited to, recently delivered/post-partum women), were identified by providers, who

Table 2 Demographic Characteristics of MWRA in Survey Districts, Baseline, and End Line

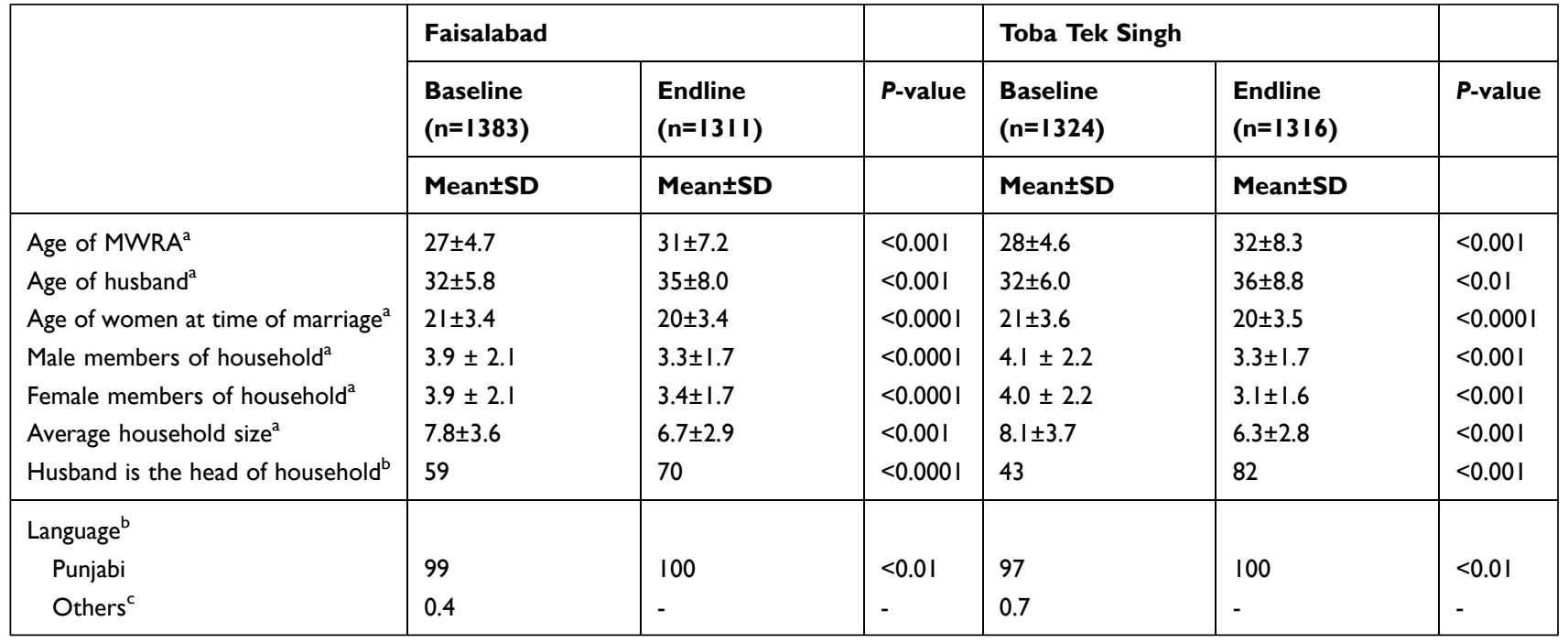

Notes: a Numbers are means. ${ }^{b}$ Percentages. ${ }^{c}$ Other includes Pushto, Hindko, and Saraiki. 
were part of the GSM provider network, in the intervention district using the poverty assessment tool. Vouchers were distributed to eligible women who were in the lowest two wealth quintiles on the poverty scale. The voucher could be redeemed for services by the project provider, with reimbursement being sent to the provider later.

\section{Sampling}

The sample size was calculated assuming that the modern method CPR would increase by up to 20 percentage points from the baseline to the end line in the intervention area and that, in the control area, it would increase by 5 percentage-points between baseline and end line. Using PASS $11^{\circledR}$ software, it was estimated that group sample sizes of at least 1276 for the intervention arm and 1276 for the control arm would produce a two-sided 95\% confidence interval for the difference in population proportions with a width of $5 \%$ when the estimated sample proportion "1" is $20 \%$, and the estimated sample proportion " 2 " is $5 \%$, and the difference in sample proportions is $15 \%$.

To recruit a sufficient number of voucher clients to ascertain if vouchers could successfully target the lowest two quintile clients, we used stratified sampling in the intervention district (Faisalabad). The sample size estimated was at least 360 voucher clients. We therefore used stratified sampling by recruiting respondents from the general population (strata 1) and voucher clients (strata 2). To ensure we recruited at least 360 voucher clients we allocated the required sample size for Faisalabad (intervention) district in two strata in a 3.5:1 (general population: voucher client) ratio whereby an oversampling of voucher clients was necessitated. Data were analysed using weighted analysis accounting for oversampling of voucher clients in the intervention arm. The final sample size, therefore, was at least 916 respondents from the general population (strata 1) and 360 voucher clients (strata 2 ) in the intervention arm.

\section{Sampling Procedure}

A multi-stage sampling strategy was used to recruit study participants for the end line household ( $\mathrm{HH})$ survey. At first stage a sampling frame of Union Councils (UC) in each district was prepared. Each UC was considered a cluster for the end line HH survey. In Faisalabad (intervention) area the total number of UCs obtained was 289 while in Toba Tek Singh (control) the total number of UCs was 84 .

Using simple random sampling (SRS) 46 UCs from the Faisalabad (intervention) were selected as a sampling frame, and sampling was stratified to recruit at least 916 respondents from the general population. For 360 voucher clients we first selected 19 GSM providers using SRS from the 100 GSM participating providers. For each selected provider we again selected 21 voucher clients from the available sampling frame of voucher clients for each provider using SRS. At the second stage we selected a HH using systematic sampling methods. For HHs with more than one eligible respondent, only one eligible woman was selected for interview. In control we selected 60 UCs (clusters) using SRS. Since the required sample size for control was 1276, this ensured that we recruited at least 20 respondents per cluster. Within the UC the HH survey was conducted, using similar methods as in Faisalabad district (Figure 1).

\section{Instrument}

A structured questionnaire was used that covered demographics, reproductive status, decision-making and contraceptive status, quality of FP services, and poverty assessment. The questionnaire was translated from English into Urdu (national language of Pakistan) back-translated and pre-tested (Table 3).

\section{Data Management}

Data collected during household surveys were double entered in a pre-designed software by two separate data operators. Measures were taken to ensure the quality of collected data. All forms were checked daily for completeness, logical errors, and cleared of irrelevant responses. Monitoring visits were also made by the PI, co-investigators, and project head office team to ensure the quality of data and adherence to the study protocol. Refresher training was arranged to emphasize understanding of data-collection tools. The software developed for data entry was also restricted for mandatory fields and extreme values. Hard copies of completed tools (questionnaires, checklists, reporting formats) were kept in locked storage before and after data entry.

\section{Data Analysis}

Data were analysed using descriptive, inferential, and regression statistics. Chi-square and $t$-test were used to compare sample characteristics between intervention and control arms to assess the differences in categorical and continuous variables, respectively. For descriptive analysis we compared the differences between baseline and end line for important project indicators. This was done for intervention and control districts separately. Chi-square was performed for variables that had sufficient cell count $(>5)$ in each category being tested. $t$-test was conducted to assess the differences in 


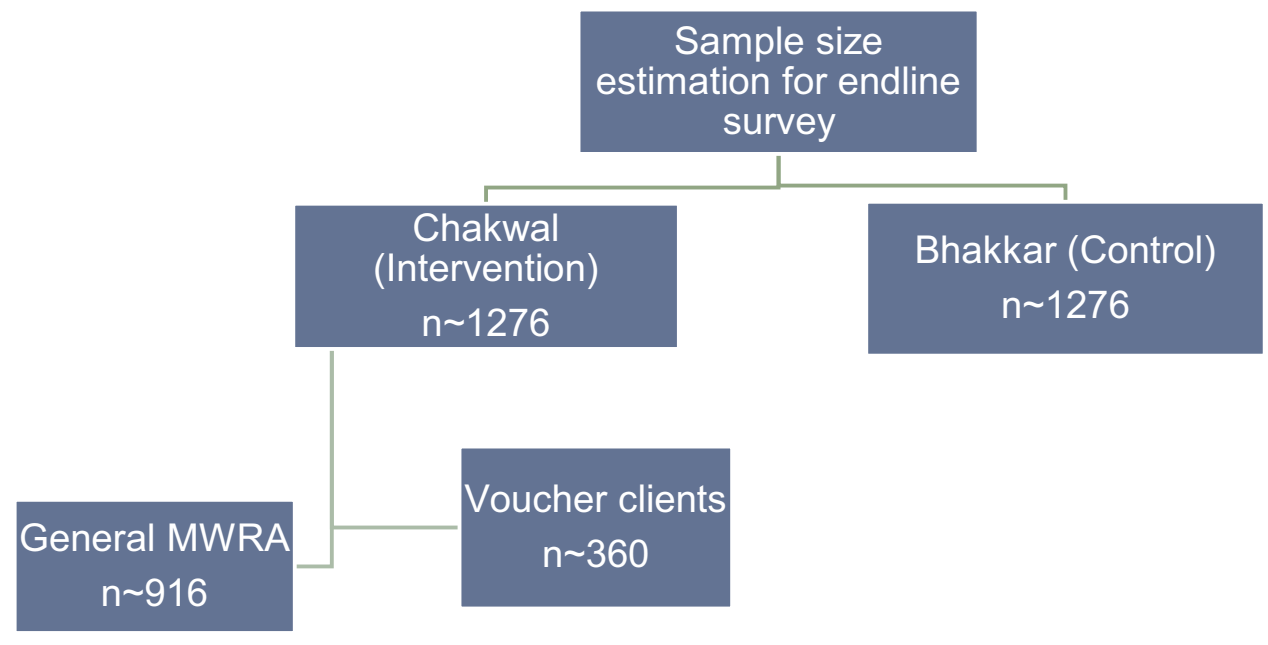

Figure I Sampling for the study.

Abbreviation: MWRA, married women of reproductive age.

continuous variables. Analysis was weighted to account for the effect of oversampling of voucher clients in intervention districts. Inferential statistics focused on isolating the effect of the intervention. Univariate Difference-in-differences (DID) estimates are reported for key contraceptive use variables. DID analysis was done by calculating 1) the change in indicators (from baseline to end line) in the control arm, 2)

Table 3 Definitions of Outcome Variables

\begin{tabular}{|l|l|}
\hline $\begin{array}{l}\text { Outcome } \\
\text { Variable }\end{array}$ & Definitions \\
\hline $\begin{array}{l}\text { Contraceptive } \\
\text { knowledge }\end{array}$ & $\begin{array}{l}\text { Aware of any one contraceptive method either } \\
\text { on spontaneous response or on probing }\end{array}$ \\
\hline Ever user & $\begin{array}{l}\text { Previously used any contraceptive method } \\
\text { (traditional and modern both) to avoid or delay } \\
\text { pregnancy }\end{array}$ \\
\hline Current user & $\begin{array}{l}\text { Currently using any contraceptive (traditional } \\
\text { and modern both) use to avoid or delay } \\
\text { pregnancy }\end{array}$ \\
\hline $\begin{array}{l}\text { Modern } \\
\text { contraceptive use }\end{array}$ & $\begin{array}{l}\text { Use of only modern methods including pill, } \\
\text { IUD, implants, condom, diaphragm/foam/jelly, } \\
\text { female sterilization, and/or male sterilization }\end{array}$ \\
\hline $\begin{array}{l}\text { First-time } \\
\text { contraceptive use }\end{array}$ & $\begin{array}{l}\text { First-time use of contraceptive methods after } \\
\text { implementation of intervention }\end{array}$ \\
\hline $\begin{array}{l}\text { Received antenatal } \\
\text { care }\end{array}$ & $\begin{array}{l}\text { Mothers who were seen by a skilled health } \\
\text { provider in at least one antenatal care visit } \\
\text { during last pregnancy }\end{array}$ \\
\hline Facility delivery & $\begin{array}{l}\text { Mothers who had delivered their child at } \\
\text { a health facility }\end{array}$ \\
\hline
\end{tabular}

change in indicators (from baseline to end line) in the intervention arm, and 3) net effect of intervention by subtracting the observed change in the control arm from the observed change in the intervention arm.

\section{Health Equity Analysis}

Household wealth index scores were used for the equity analysis. Asset-based wealth indices were derived from principal component analysis. Subsequently, the scores were divided into quintiles with quintile 1 (Q1) indicating the poorest $20 \%$ of households and quintile 5 (Q5) representing the richest. We used one absolute (the slope index of inequality (SII)) $)^{21,22}$ and two relative measures (the ratio of Q5 to Q1, and the concentration index) to assess the extent and degree of inequalities. As absolute and relative measures can produce different results that may lead to different conclusions, both measures were essential in order to get a clear picture of inequalities. The SII was calculated with logistic regression rather than with the traditional linear regression approach to avoid predicting values in the regression model that were outside the interval between 0 and 1 . The SII uses the coverage values in the difference in percentage points between individuals at the top and bottom of the wealth scale. SII was determined/worked out by regressing all/each of the seven outcomes against an individual's relative rank in the cumulative distribution of socioeconomic position.

\section{Concentration Curve}

In order to assess differences in horizontal equity among voucher clients and the general population of MWRA, a concentration index and curves were generated. The 
concentration curve was drawn to display the degree of inequality by plotting the cumulative proportion of modern contraceptive method use on the Y-axis against the cumulative proportion of population on the $\mathrm{X}$-axis, ranked from poorest to richest. The line of equality or the 45-degree line means an equitable distribution of modern contraceptive use among the study population, irrespective of household socioeconomic status. If the concentration curve lies above the line of equality, it indicates a pro-poor utilization of modern contraceptive methods with the population. If the concentration curve lies below the line of equality, it indicates a pro-rich utilization of modern contraceptive methods. The distance between any concentration curve and the line of equality indicates the degree of inequality, with the uppermost (lower most) concentration curve showing the most pro-poor (pro-rich) distribution.

\section{Concentration Index}

The concentration index is also another measure that indicates the magnitude of inequality. ${ }^{23}$ The index indicates the extent to which a health or services indicator is concentrated among the disadvantaged or the advantaged. This index is directly related to the concentration curve and is defined as the area between the concentration curve and the 45-degree line (line of equality). We estimated the concentration index for voucher clients and non-voucher clients to determine equality in the use of modern contraceptive method. This index indicates the extent to which a health or services indicator is concentrated among the disadvantaged or the advantaged. The concentration index gives values ranging from -1 to 1 . When the concentration index value is 0 it indicates there is no inequality - ie, access to health services (utilization of modern contraceptive methods) makes no difference among poor and rich population. The negative value indicates a relatively higher utilization of modern contraceptive use among the poor. A positive value of the index indicates a comparatively higher utilization of contraceptive method among the advanced or better off population. All analyses at both the univariate and multiple regression stages were adjusted for the probability sample weights. Statistical analyses were performed using Stata version 13.1 Software (StataCorp, College Station, TX, USA).

\section{Ethics Approval and Consent to Participate}

All respondents were informed about the survey and their rights. No personal information was entered in the database that could be used to identify specific individuals. The study protocol was reviewed and approved by Population Services International (PSI) Research Ethics Board (REB). ${ }^{19,20}$ All survey participants provided written informed consent.

\section{Results}

We report the key findings of the study.

\section{Demographic Characteristics} Marital Status and Age Structure

All study participants were married women. The age distribution indicates an increase of 4 years in intervention (baseline: 27 years, end line: 31 years) and in the control areas (baseline: 28 years, end line: 32 years). The average household showed a reduction in size from 7.8 to 6.7 and 8.1 to 6.3 persons per household in intervention and control areas, respectively. The majority language spoken in both intervention and in control areas was Punjabi (Table 2).

\section{Contraceptive Uptake and Knowledge Current Contraceptive Use}

Current contraceptive uptake increased significantly in intervention areas by $23 \%$, ie, from $24 \%$ at baseline to $47 \%$ at end line. In the control group women reported a significant increase of $18 \%$ in current contraceptive uptake, from $23 \%$ at baseline to $41 \%$ at end line. Among current users, modern contraceptive method use increased significantly by $15 \%$ (baseline: $18 \%$, endline: $33 \%$ ) in the intervention area. A similar significant increase of $15 \%$ is observed in the control area also (baseline: 17\%, endline: $32 \%$ ). The method mix in Table 4 provides a breakdown of specific method current contraceptive use. In the intervention area, the most significant increase was noted in female sterilization, which increased by $11 \%$ (from $5 \%$ to $16 \%$ ) in the intervention group, and for withdrawal usage, which increased by $5 \%$ (baseline: $6 \%$, end line: $11 \%$ ) followed by a $3 \%$ increase in IUD use (baseline: $2 \%$, end line: $5 \%$ ). In the control area, female sterilization use increased by 10 percentage points, ie, from $4 \%$ at baseline to $14 \%$ at end line. Female sterilization, IUDs, and injections also increased at end line (Table 4).

\section{Overall Ever Use of Contraceptive Methods}

Ever use of contraception increased in both intervention and control areas. In intervention areas there was a significant increase of $25 \%$ (baseline: $40 \%$, end line: 
Table 4 Current Contraceptive Use Method Mix

\begin{tabular}{|c|c|c|c|c|c|c|}
\hline & \multicolumn{2}{|l|}{ Faisalabad } & \multirow[t]{3}{*}{$P$-value } & \multicolumn{2}{|l|}{ Toba Tek Singh } & \multirow[t]{3}{*}{$P$-value } \\
\hline & Baseline $(n=\mid 383)$ & Endline $(n=|3| I)$ & & Baseline $(n=1324)$ & Endline $(n=|3| 6)$ & \\
\hline & $\%$ & $\%$ & & $\%$ & $\%$ & \\
\hline Overall current use & 23 & 43 & $<0.0001$ & 23 & 38 & $<0.0001$ \\
\hline Modern method & 17 & 32 & $<0.0001$ & 18 & 33 & $<0.0001$ \\
\hline Pill & 1 & - & - & I & - & - \\
\hline IUD & 2 & 5 & $<0.0001$ & 2 & 5 & $<0.0001$ \\
\hline Injections & 1 & - & - & 2 & 5 & $<0.0001$ \\
\hline Condom & 8 & 11 & 0.0078 & 11 & 10 & 0.402 \\
\hline Female sterilization & 5 & 16 & $<0.0001$ & 4 & 14 & $<0.0001$ \\
\hline Traditional method & 6 & 11 & $<0.0001$ & 5 & 5 & - \\
\hline Periodic abstinence & I & - & - & 1 & - & - \\
\hline Withdrawal & 6 & 11 & $<0.0001$ & 4 & 5 & 0.2152 \\
\hline
\end{tabular}

Note: Other methods were $<1 \%$ at baseline in Toba Tek Singh.

$65 \%, P<0.01$ ), however, in control areas the increase was $17 \%$ but statistically insignificant (baseline: $38 \%$, end line: $55 \%, P 0.07)$.

\section{Contraceptive Information}

Overall information of at least one contraceptive method increased in intervention areas by $5 \%$ (baseline: $92 \%$, end line: $97 \%, P 0.45$ ) and in control areas by $3 \%$ (baseline: 92\%, end line: $95 \%, P$ 0.79). In intervention and control areas at both base and end lines, the most common known contraceptive method was pills and injections.

\section{Method Discontinuation and Switching}

At end line, participants were asked about use, discontinuation, and switching of any modern contraceptive method during the last 2 years. In the intervention district, 722 (55\%) women reported using a modern contraceptive method during the last 24 months. Of these, 16\% reported discontinuing modern contraceptive use while $3 \%$ had switched to a modern contraceptive during the same time. In the control district, 504 (38\%) women reported using a modern contraceptive method during the last 24 months. Women discontinuing modern contraceptive use in the control areas were four percentage points greater at $20 \%$, while only $2 \%$ of women had switched to a modern method during the last 2 years, compared to the intervention area. The difference was not found to be significant $(P 0.07)$.

Women in the intervention and control areas mainly discontinued due to a desire for more children (intervention: 53\%, control: 51\%), and pregnancy due to method failure (intervention areas $6 \%$, control areas 13\%) (Table 5).
Women who reported switching to a modern method during the past 24 months were also asked about which method they switched to. The two most common methods women switched to were condoms (30\%) and IUD (30\%) in intervention areas, while women in control areas most commonly switched to condoms (50\%) followed by pills $(25 \%)$.

Table 5 Modern Contraceptive Use Discontinuation and Reason for Discontinuation During the Last 2 Years, Measured at Endline

\begin{tabular}{|c|c|c|}
\hline \multirow[t]{3}{*}{$\begin{array}{l}\text { Respondents Reporting Using } \\
\text { Modern Method in Last } 24 \text { Months }\end{array}$} & Faisalabad & $\begin{array}{l}\text { Toba } \\
\text { Tek } \\
\text { Singh }\end{array}$ \\
\hline & $(n=722)$ & $(n=502)$ \\
\hline & n (\%) & n (\%) \\
\hline a) Discontinuation (number of episodes) & $113(16)^{a}$ & $99(20)^{\mathrm{a}}$ \\
\hline Method discontinued & $n=113$ & $n=99$ \\
\hline Pills & $12(10.7)$ & $7(7)$ \\
\hline IUD & $5(4)$ & $20(20)$ \\
\hline Injection & $19(17)$ & $13(13)$ \\
\hline Condom & $60(53)$ & $59(59)$ \\
\hline b) Reasons for discontinuation & $\mathrm{n}=113$ & $n=99$ \\
\hline Want more children & $53(47)$ & $5 \mathrm{I}(5 \mathrm{I})$ \\
\hline Infrequent sex/No sex & $6(5)$ & $3(3)$ \\
\hline Health concerns & $4(3.5)$ & $6(6)$ \\
\hline Husband partner disapproved & $2(2)$ & $I(I)$ \\
\hline Became pregnant while using & $6(5)$ & $13(13)$ \\
\hline Other* & $2(2)$ & $2(2)$ \\
\hline No reasons cited & $27(24)$ & $24(24)$ \\
\hline
\end{tabular}

Notes: ${ }^{a} P$-value $>0.05$. Explanatory note: ${ }^{*}$ Other includes: Wanted more effective method, costs too much, lack of access/too far, inconvenient to use (endline only). 


\section{Immunization Coverage \\ Vaccines Received}

Difference in difference analysis shows that the intervention area did not record a significant increase in vaccination for ever vaccinated children (Table 6). For individual vaccines, the intervention area coverage increased for BCG $(84 \%$ to $91 \%$ ), DPT (78\% to $84 \%$ ), HBV (52\% to $82 \%$ ), and measles ( $42 \%$ to $79 \%$ ) vaccines between baseline and end line. The increase for $\mathrm{HBV}$ and measles vaccines was significant.

\section{Targeting Voucher Clients}

Distribution of voucher clients according to poverty assessment (based on a poverty assessment tool) indicates that $40 \%(n=409)$ of the voucher clients fulfilled the poverty assessment criteria. FP visit was the main (86\%) service used by voucher clients through the voucher scheme, followed by immunization visits (54\%). The main FP method used by voucher clients was IUD (39\%), followed by injections $(29 \%)$, condoms (18\%), and pills $(12 \%)$.

Furthermore, the satisfaction of voucher clients with respect to attributes of service quality (figures not shown here) was highest for friendliness and respect received from providers and at the health facilities. Cleanliness and length of time spent waiting to be seen at the facility were the least satisfactory.

\section{Difference in Difference Analysis}

Despite increases in both intervention and control sites, there was no net increase in modern contraceptive use among the study participants. Current use and ever use of modern contraceptives increased significantly by net $5 \%$ and $8 \%$, respectively. Method-specific net increases were noted for condoms (4\%) and female sterilization (1\%) (Table 7).

\section{Vouchers and Modern Contraceptive Use}

Modern contraceptive method use in the intervention group among voucher recipients and the general population is shown in Figure 2. Bivariate analysis (left panel) indicated that around $84 \%$ of voucher clients used modern methods, whereas 34\% MWRA in the general population used modern methods $(P<0.001)$. Univariate model (unadjusted) found significantly higher odds ratio $(\mathrm{OR}=10.2$; 95\% CI=7.5-13.7) of modern contraceptive use for voucher clients compared to MWRA from the general population. The multivariable logistic regression analysis (right panel) showed that voucher clients were $14.2 \quad(95 \%$ $\mathrm{CI}=10.1-19.8$ ) times more likely to use modern contraceptives compared to the general population (Figure 3).

\section{Health Equity Analysis: Differences in Contraceptive and Maternal Health-Care Uptake by Wealth Index}

Table 8 presents the use of contraceptive methods and maternal health services by women in the poorest and the richest quintile, based on baseline and endline data. The table also includes the summary equity indices and shows the results of inequality in contraceptive use and maternal health services in Greenstar Project areas. Both absolute and relative inequality measures are also presented.

The percentage difference (SII) of contraceptive ever use from poorest-to-richest was $3 \%$ in the intervention group,

Table 6 Vaccine Coverage in Intervention and Control Areas

\begin{tabular}{|c|c|c|c|c|c|c|c|}
\hline & \multicolumn{2}{|l|}{ Control } & \multicolumn{2}{|c|}{ Intervention } & \multirow{2}{*}{\multicolumn{2}{|c|}{ 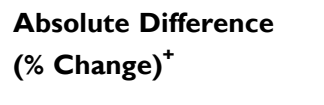 }} & \multirow[t]{3}{*}{ Net Effect (\% Change) } \\
\hline & \multirow{2}{*}{$\begin{array}{l}\text { Baseline } \\
\%\end{array}$} & \multirow{2}{*}{$\begin{array}{l}\text { Endline } \\
\%\end{array}$} & \multirow{2}{*}{$\begin{array}{l}\text { Baseline } \\
\%\end{array}$} & \multirow{2}{*}{$\begin{array}{l}\text { Endline } \\
\%\end{array}$} & & & \\
\hline & & & & & Control & Intervention & \\
\hline Ever vaccinated ${ }^{a}$ & 95 & 81 & 96 & 92 & -14 & -4 & $-10^{\mathrm{e}}$ \\
\hline $\mathrm{BCG}^{\mathrm{b}}$ & 87 & 80 & 84 & 91 & -7 & 7 & $14^{\mathrm{f}}$ \\
\hline Polio & 96 & 80 & 96 & 92 & -14 & -4 & $-10^{\mathrm{e}}$ \\
\hline Average doses of polio - mean (SD) ${ }^{c}$ & $5.5(1.9)$ & $6.8(1.0)$ & $5.5(2.1)$ & $6.4(1.6)$ & -0.9 & -0.5 & $-0.4^{\mathrm{e}}$ \\
\hline DPT & 76 & 77 & 78 & 84 & I & 6 & $5^{f}$ \\
\hline Average doses of DPT - mean (SD) ${ }^{d}$ & $2.4(3.2)$ & $3.0(0.3)$ & $3.1(7.5)$ & $2.4(0.9)$ & -2.9 & -6.4 & $-3.5^{\mathrm{e}}$ \\
\hline HBV & 50 & 75 & 52 & 82 & 25 & 30 & $5^{f}$ \\
\hline Measles & 36 & 68 & 42 & 79 & 32 & 37 & $5^{f}$ \\
\hline
\end{tabular}

Notes: ${ }^{a} n=1306,1240$ at baseline in Faisalabad and Toba Tek Singh. ${ }^{b} n=1146,1136$ at baseline in Faisalabad and Toba Tek Singh. ${ }^{c} n=849,757$ at endline in Faisalabad and Toba Tek Singh. ${ }^{d} n=786,716$ at endline in Faisalabad and Toba Tek Singh, $n=1026,997$ at baseline Faisalabad and Toba Tek Singh group. ${ }^{e} P$-value $>0.05$. ${ }^{f} P$-value $<0.05$. Explanatory Notes: "Absolute difference is the percentage change from baseline to endline in each Study "B" arm separately. "Net effect is the percentage change in intervention group subtracting the percentage change in control. 
Table 7 Difference in Difference Analysis for Ever Use, Current Contraceptive Use by Type and Method

\begin{tabular}{|c|c|c|c|c|c|c|c|}
\hline & \multicolumn{2}{|l|}{ Control } & \multicolumn{2}{|c|}{ Intervention } & \multicolumn{2}{|c|}{ Absolute Difference (\% Change) ${ }^{+}$} & \multirow[t]{2}{*}{ Net Effect (\% Change) ${ }^{\wedge}$} \\
\hline & $\begin{array}{l}\text { Baseline } \\
\text { (\%) }\end{array}$ & $\begin{array}{l}\text { Endline } \\
\text { (\%) }\end{array}$ & $\begin{array}{l}\text { Baseline } \\
\text { (\%) }\end{array}$ & $\begin{array}{l}\text { Endline } \\
\text { (\%) }\end{array}$ & Control & Intervention & \\
\hline Ever user & 38 & 55 & 40 & 65 & 17 & 25 & $8^{c}$ \\
\hline Current user ${ }^{d}$ & 23 & 38 & 23 & 43 & 15 & 20 & $5^{\mathrm{b}}$ \\
\hline Modern method ${ }^{e}$ & 18 & 33 & 17 & 32 & 15 & 15 & $0^{\mathrm{b}}$ \\
\hline Pill & I & 0 & I & 0 & -1 & -1 & $0^{\mathrm{b}}$ \\
\hline$I_{U} D^{a}$ & 2 & 5 & 2 & 5 & 3 & 3 & $0^{\mathrm{b}}$ \\
\hline Injections & 2 & 5 & I & 0 & 3 & -1 & $-4^{c}$ \\
\hline Condom & 11 & 10 & 8 & 11 & -1 & 3 & $4^{\mathrm{b}}$ \\
\hline Female sterilization & 4 & 14 & 5 & 16 & 10 & 11 & $\mathrm{I}^{\mathrm{b}}$ \\
\hline Traditional method ${ }^{f}$ & 5 & 5 & 6 & 11 & 0 & 5 & $5^{c}$ \\
\hline Periodic abstinence & I & 0 & I & 0 & -1 & -1 & $0^{\mathrm{b}}$ \\
\hline Withdrawal & 4 & 5 & 6 & 11 & I & 5 & $4^{c}$ \\
\hline
\end{tabular}

Notes: ${ }^{a}$ Intrauterine device. ${ }^{b} P$-value $>0.05 .{ }^{c} P$-value $<0.05 .{ }^{d}$ Total of percentages for $2+3 .{ }^{~}$ Modern methods: Includes pill, IUD, implants, condom, diaphragm/foam/jelly, female sterilization, and/or male sterilization. ${ }^{f}$ Traditional methods: includes abstinence and with-drawl method. ${ }^{+}$Absolute difference is the percentage change from baseline to endline in each Study "B" arm separately. "Net effect is the percentage change in intervention group subtracting the percentage change in control group.

indicating that women in the richest quintile were $3 \%$ more likely to ever use a contraceptive (Table 8).

The poorest-richest difference (SII) for current contraceptive use was $-0.9 \%$ in intervention areas, followed by $-0.1 \%$ for modern method use, $-2.3 \%$ for first-time modern-method use, $-1.3 \%$ for knowledge of contraceptives, $-15 \%$ for receiving ANC and $-16 \%$ for delivery at a health facility. These negative findings suggest that women in the richest quintiles were less likely to be associated with the above outcomes compared to women in the poorest quintile (Table 8).
Concentration index values for modern contraceptive use, first-time use of modern contraceptives, knowledge of contraceptives, receiving ANC, and delivery at health facilities were negative in intervention areas, indicating that the use of these services was more concentrated among the disadvantaged (poor) in intervention areas (Table 8).

\section{Concentration Curves}

Figure 2 provides a graphic representation of the distribution of modern contraceptive method use by

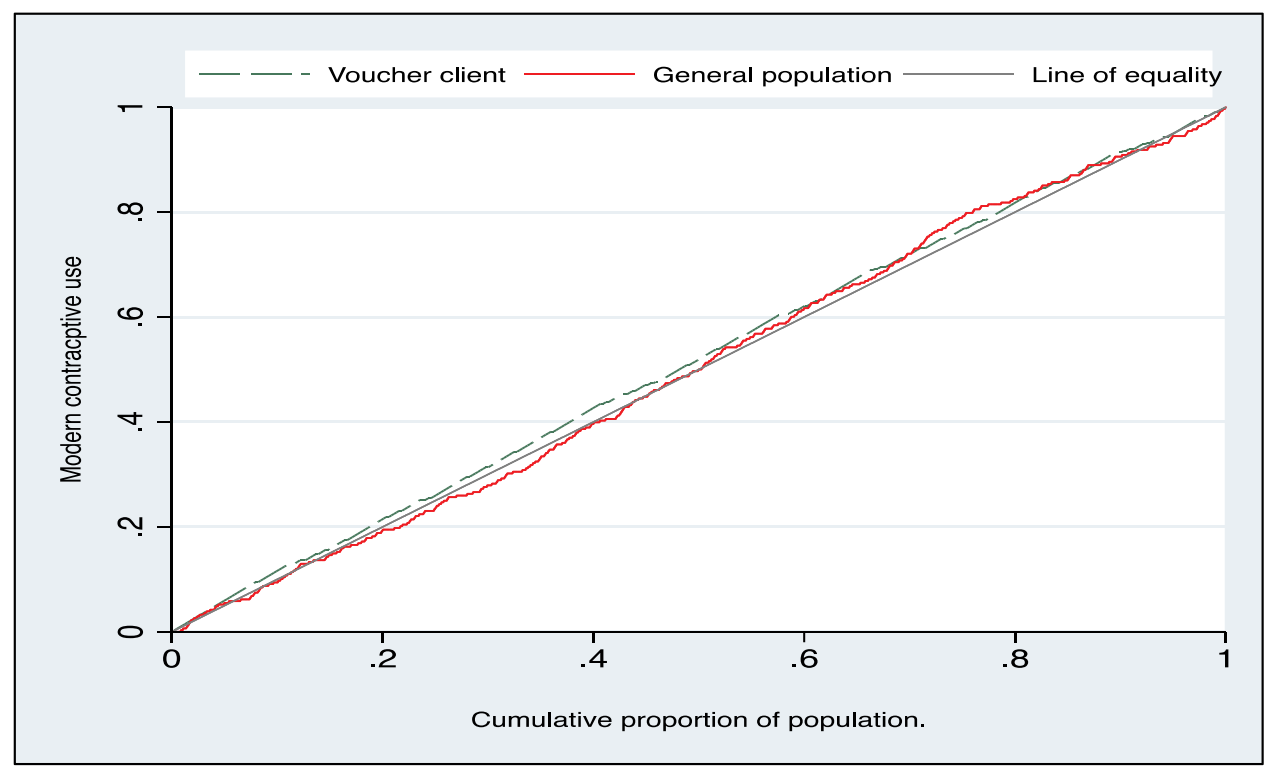

Figure 2 Concentration index, $-0.029(95 \% \mathrm{Cl}=-0.054-0.005 ; P=0.02)$ for the voucher client and $-0.006(95 \% \mathrm{Cl}=-0.058-0.0464 ; P=0.82)$ for the general population. 

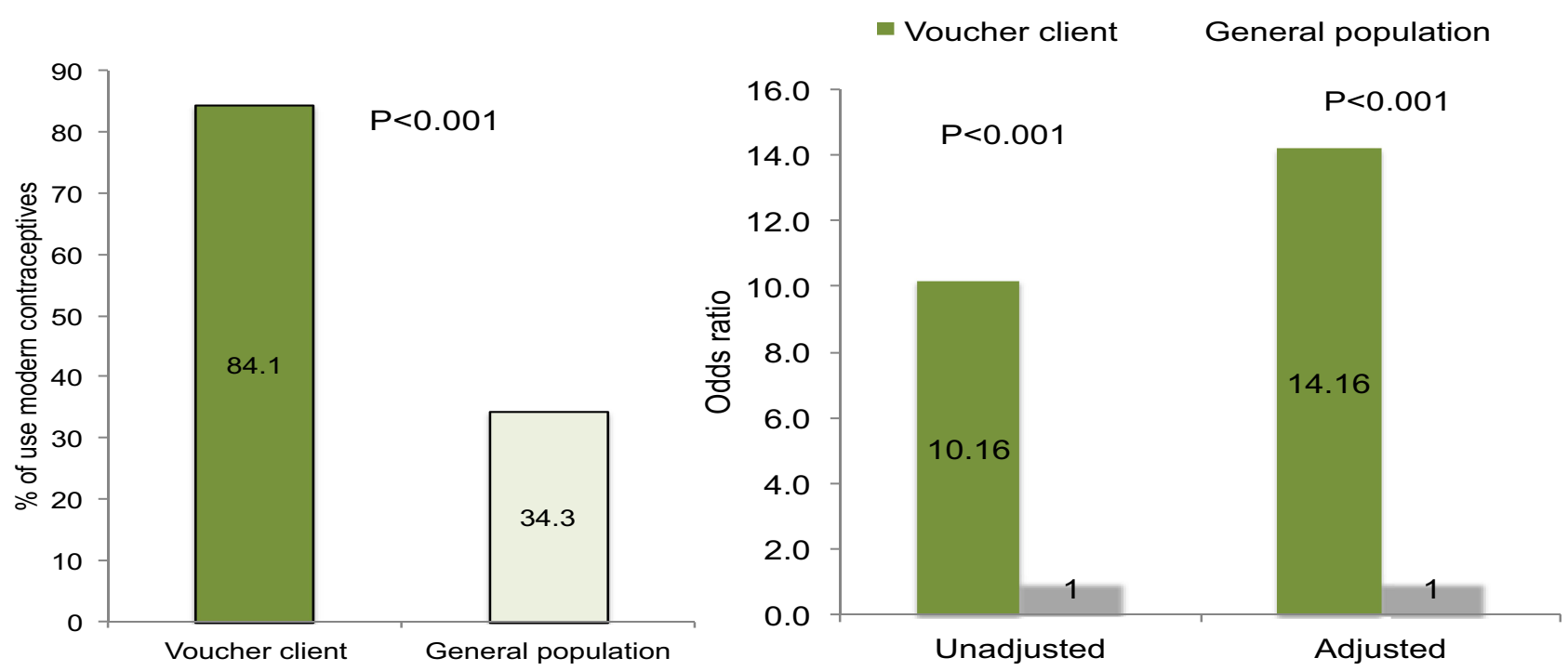

Figure 3 Adjusting confounding variables respondents' age, husbands' age, respondents' education, husbands' education, household size, and socioeconomic status; general population is the reference category for logistics regression.

voucher clients and general population MWRA according to wealth status in the Greenstar intervention group. Visually comparing the two curves, an increase in inequality can be seen if the curve shifts further from the line of equity. The concentration curve of voucher clients is very close (and just above) the line of equity, indicating a higher concentration of modern contraceptive use among poor women compared to women from the richer wealth status. The voucher client concentration curve approached the line of equality, suggesting that there was very low inequality and in terms of access to modern contraceptives there is equality between rich and poor among voucher clients.

The concentration indexes confirm what was observed in the curves. The concentration index of voucher clients had a negative value close to zero $(-0.029,95 \% \mathrm{CI}=$ $-0.054-0.005 ; P=0.02$ ) indicating that a greater proportion of the population with a lower wealth status uses modern contraceptive methods than those with a higher wealth status. The concentration curve for the general population is less clear-cut; $50 \%$ of the curve is below the diagonal line, with the remainder above it. However, the concentration index is negative and close to zero $(-0.006,95 \% \mathrm{CI}=$ $-0.058-0.0464 ; P=0.82)$, indicating that the use of modern contraceptive methods was pro-poor, and that the poor-torich difference is minimal in access to modern contraceptive methods.

\section{Discussion}

Several important findings emerge from our analysis. Firstly, the results indicated that targeted provision of subsidized FP services through a multi-purpose voucher scheme was not effective enough to have a net increase in demand and use of modern contraceptives in an intervention area compared to the control area.

However, the overall current use of contraceptives did increase significantly from baseline in intervention areas by $23 \%$ compared to the control group at $18 \%$ in current contraceptive use at the endline. There was a net increase of $5 \%$ in any contraceptive method use by women in the intervention arm. To note, this was primarily driven by traditional method use and was not the main outcome of interest for this study.

A possible explanation can be that, compared to baseline, results in the end line survey noted that most women obtained contraceptive methods from public sector providers working under the umbrella of population welfare and health departments. All these programs have family planning and immunization provision in their scope of work. However, triangulating the exact attribute to the gains in the control group was not possible as that would have required additional field operations with intensive requirements for financial, time, and human resource. There is the possibility that, during the course of the project, the services at public sector outlets improved in the control areas of the project, nullifying the gain in modern contraceptive uptake in the intervention 
Table 8 Magnitude of Inequalities in Contraceptive and Health Services Use in Greenstar Project Areas

\begin{tabular}{|c|c|c|c|c|c|c|}
\hline \multirow[t]{2}{*}{ Characteristics } & \multicolumn{3}{|l|}{ Coverage (\%) } & \multicolumn{3}{|c|}{ Inequality Assessment } \\
\hline & Overall & QI (Poorest) & Q5 (Richest) & $\begin{array}{l}\text { SII (Q5: QI, \% } \\
\text { points) }\end{array}$ & RII (Q5:QI) & $\begin{array}{l}\text { Concentration } \\
\text { Index }(x \mid 00)\end{array}$ \\
\hline \multicolumn{7}{|l|}{ Intervention areas } \\
\hline Ever use & $41.0(39.1-42.8)$ & $37.9(34 .|-4| .8)$ & $41.2(37.0-45.3)$ & $3.2(-2.5-8.8)$ & I.I (0.9-I.5) & $0.8(-0.1-2.7)$ \\
\hline Current user & $23.9(22.2-25.5)$ & $23.7(20.3-27.1)$ & $22.9(19.3-26.4)$ & $-0.9(-5.8-4.0)$ & $1.0(0.8-1.2)$ & $2.2(-0.3-4.7)$ \\
\hline Modern-method user & $17.4(16.0-18.9)$ & $17.6(14.6-20.6)$ & $16.6(13.5-19.8)$ & $-0.1(-5.3-3.4)$ & I.I (0.8-I.4) & $-0.8(-1.4--0.2)$ \\
\hline First-time use & $74.6(71.2-77.9)$ & $83.7(76.3-91)$ & $81.4(74.0-88.7)$ & $-2.3(-12.6-8.1)$ & $0.7(0.3-1.4)$ & $-0.5(-3.1-2.1)$ \\
\hline Knowledge & $94.6(93.7-95.4)$ & $93.9(91.8-96)$ & $93.5(91.5-95.5)$ & $-1.3(-4.0-1.4)$ & $0.8(0.5-1.3)$ & $-0.5(-1.0-0.01)$ \\
\hline $\mathrm{ANC}^{\mathrm{a}}$ & $82.0(80.5-83.5)$ & $86.6(83.5-89.6)$ & $72.1(68.4-75.8)$ & $-14.7(-19.4--10.0)$ & $0.4(0.3-0.5)$ & $-3.3(-4.3--2.2)$ \\
\hline Delivery at health facilities & $66.2(64.4-68.0)$ & $73.3(69.4-77.2)$ & $57.8(53.8-6 \mid .9)$ & $-16.3(-22.0--10.6)$ & $0.5(0.4-0.6)$ & $-4.6(-6.2--3.0)$ \\
\hline \multicolumn{7}{|l|}{ Control areas } \\
\hline Ever use & $39.1(37.2-41.0)$ & $35.1(30.6-39.7)$ & $38.6(34.4-42.9)$ & $3.7(-2.5-10.0)$ & $1.0(0.8-1.3)$ & $-0.8(-3.3-1.8)$ \\
\hline Current user & $24.0(22.3-25.7)$ & $20.2(16.3-24.0)$ & $21.7(18.1-25.3)$ & I.8 $(-3.5-7.0)$ & I.I (0.8-I.4) & $-2.3(-5.7-1.2)$ \\
\hline Modern-method user & $19.0(17.5-20.6)$ & $16.5(13.0-20.1)$ & $14.7(11.6-17.8)$ & $-1.7(-6.4-3.0)$ & $0.7(0.6-1.0)$ & $0.3(-0.3-0.9)$ \\
\hline First time use ${ }^{b}$ & $67.6(63.2-72.0)$ & $70.0(62.0-78.0)$ & $76.0(65.6-86.4)$ & $6.0(-7.1-19.0)$ & $1.4(0.7-2.8)$ & $2.2(-1.6-6.0)$ \\
\hline Knowledge & $93.8(92.9-94.8)$ & $96.0(94.3-97.6)$ & $93.6(91.4-95.8)$ & $-2.1(-5.1-0.9)$ & $0.6(0.4-1.1)$ & $-0.4(-1.0-0.2)$ \\
\hline $\mathrm{ANC}^{\mathrm{a}}$ & $87.4(86.1-88.8)$ & $90.3(87.7-92.8)$ & $79.6(75.9-83.3)$ & $-8.9(-13.1--4.7)$ & $0.5(0.3-0.7)$ & $-2.0(-2.9--1.1)$ \\
\hline Delivery at health facilities & $56.9(54.9-58.8)$ & $61.6(57.5-65.7)$ & $42.1(37.6-46.5)$ & $-20.0(-26.0--13.9)$ & $0.4(0.3-0.6)$ & $-8.1(-10.1--6.1)$ \\
\hline
\end{tabular}

Notes: ${ }^{a}$ First-time contraceptive use. ${ }^{b}$ Received antenatal care from skilled birth attendants. Explanatory note: All equity analysis was adjusted for baseline and endline survey points.

Abbreviations: SII, slope index inequality; RII, relative index inequality; $95 \% \mathrm{Cl}, 95 \%$ confidence interval.

arm of the project. This is an area that needs to be explored further by program managers of the GSM Project.

\section{Discontinuation and Switching}

The intervention had some effect in reducing modern method discontinuation in the 2 years preceding the survey. The performance of the intervention area to enhance continuous use of modern contraceptives is an encouraging sign and has the potential to be used as a launching pad for future FP service provision.

\section{Targeting the Underserved}

The result noted that only $40 \%$ of the women who received vouchers belonged to the two lowest socioeconomic quintiles. This can be explained by the fact that some women, in addition to eligibility criteria for poverty, might have received vouchers based on need for capacity-to-benefit (defined as a woman is given a free service voucher if she reports lack of access to finances, irrespective of what her poverty-ranking score is) ${ }^{24}$ to enhance social empowerment. Furthermore, a study stated that "need only exists if there is capacity to benefit from a health-care service". ${ }^{25}$ This highlights the outcomes to be achieved by allocating resources on the basis of need that also promotes efficiency by directing attention to interventions that produce the most benefit. ${ }^{26}$ Besides using poverty assessment criteria, it is important to carefully consider options that can maximally benefit the lowest quintile such as regional or geographical targeting for future FP financing initiative.

\section{Equity in Contraceptive Use}

In this intervention, both slope index of inequality and concentration index for modern contraceptive use, firsttime use of modern contraceptives, knowledge of contraceptives, receiving ANC and delivery at health facilities were negative in intervention areas. This finding shows that these indicators were concentrated among the disadvantaged women (poor quintiles) in intervention areas. The concentration curve of voucher clients was observed to be very close to the line of equity, suggesting equality in terms of access to modern contraceptives between rich and poor women.

Therefore, the health equity analysis findings demonstrate the effectiveness of the intervention in improving contraceptive ever use, current contraceptive use, modern 
contraceptive use, and first-time modern contraceptive use among the most deserving segments of the population. Disparity in the distribution of vouchers to potential clients in terms of poverty assessment might be one of the reasons for the lack of effectiveness of project interventions on some contraceptive uptake outcomes in the project.

\section{Policy Implications}

In the past decade, voucher programs have increasingly been implemented to channel subsidies from governments and donors to disadvantaged populations in order to stimulate demand for specific health services by subsidizing access via accredited and contracted healthcare facilities and providers.

In many Lower-Middle Income Countries (LMICs), uptake of short-term modern contraceptives such as the condom or the pill, has substantially increased in response to FP program initiatives, usually with one or two methods dominating the method mix. But significant inequities and disparities remain, particularly to access highly effective long-acting reversible contraception (LARC) and permanent contraception. Although initial financial costs to obtaining these methods are higher, the cost per month over the long term is often lower than less-effective, shortterm methods. These long-term methods are, however, often out of reach of the most vulnerable and marginalized women. In developing countries, in order to bridge this equity gap, national governments, donors, and NGOs are collaborating to expand access to modern contraceptives, particularly LARCs, by testing and implementing strategies aimed at increasing affordability both on the demand and supply side.

In the efforts to enhance method mix, GSM voucher intervention had a positive impact on key contraceptives indicators in intervention areas. While the GSM voucher model did not demonstrate a substantial net gain in modern contraceptive use, it was effective in increasing any and first-time contraceptive uptake among disadvantaged segments of the population in the intervention areas. This model also used a subsidized approach rather than providing free services, it will be important for decision-makers to evaluate the usefulness of this approach, as long-term provision of free services can lead to dependency in targeted communities.

Poor women living in intervention sites were more likely to have higher uptake of child immunization and contraceptives methods than in sites not served by the voucher program and it seems a promising approach which requires further implementation experience and impact documentation. ${ }^{27}$

Voucher programs have their strengths; they are a proven approach to increasing the use of priority services, ${ }^{28}$ improve equity, have a positive impact on the quality of services, ${ }^{29}$ and can lead to a higher rate of continuation of modern methods. Vouchers are a promising mechanism to reach out to the poor and underserved in countries where social health insurance is not yet feasible. Vouchers are a promising approach to target subsidies to individuals who, in the absence of the subsidy, are less likely to have sought care, thus enhancing equity. However, any scheme introduced in the public sector will depend on the quality of service provision (counseling, commodity provision) and monitoring to ensure the standards in services in the public sector.

\section{Conclusion}

Although this low-cost multipurpose voucher model was not able to demonstrate an increase in net modern contraceptive use through the private sector, some gains were noted, such as an increase in method-specific contraceptive use, better child immunization status, and a positive impact on equity. Policy-makers may review and adapt the available approaches in local context to effectively reach the underserved and deserving in increasing contraceptive services to achieve national goals.

\section{Disclaimer}

This paper contains the collective views of an international group of experts, and does not necessarily represent the decisions or the stated policy of the World Health Organization.

\section{Abbreviations}

DID, Difference-in-differences; FP, family planning; GSM, Greenstar Social Marketing; HH, household; LMIC, lower-middle income countries; $\mathrm{MCH}$, maternal child health; $\mathrm{mCPR}$, modern contraceptive prevalence rate; MWRA, married women of reproductive age; PNC, postnatal care; PSI, Population Services International; SRS, simple random sampling; SII, slope index of inequality; UC, Union Council; WHO, World Health Organization.

\section{Data Sharing Statement}

The data will be available on request from the corresponding author. 


\section{Ethics Approval and Consent to Participate}

This paper reviewed national policies. The data were completely anonymous with no personal identifiers. The study was reviewed and approved by Population Services International (PSI) Research Ethics Board (REB). ${ }^{19,20}$

\section{Consent for Publication}

Not applicable.

\section{Acknowledgments}

The authors are highly indebted to all the enumerators, field workers; and, above all, to the study participants for their time and enriching this study by sharing their experiences.

\section{Author Contributions}

This evaluation was conceptualized and conducted by MA, SKA, HBH, and MMR independently without any consultation with the project implementing organization. All authors made a significant contribution to the work reported, whether that is in the conception, study design, execution, acquisition of data, analysis and interpretation, or in all these areas; took part in drafting, revising, or critically reviewing the article; gave final approval of the version to be published; have agreed on the journal to which the article has been submitted; and agree to be accountable for all aspects of the work.

\section{Funding}

Funded by The David and Lucile Packard Foundation, this evaluation is conducted by the Department of Reproductive Health and Research, World Health Organization, Geneva. The paper includes collective views of an international group of experts, and does not necessarily represent the decisions or the stated policy of the World Health Organization, or The David and Lucile Packard Foundation.

\section{Disclosure}

The authors have no conflicts of interest.

\section{References}

1. World Health Organization. Ensuring Human Rights in the Provision of Contraceptive Information and Services: Guidance and Recommendations. Geneva: World Health Organization; 2014.
2. Starbird E, Norton M, Marcus R. Investing in family planning: key to achieving the sustainable development goals. Glob Health Sci Pract. 2016;4(2):191-210. doi:10.9745/GHSP-D-15-00374

3. Cleland J, Conde-Agudelo A, Peterson H, Ross J, Tsui A. Contraception, and health. Lancet. 2012;380:149-156. doi:10.1016/ S0140-6736(12)60609-6

4. Guttmacher Institute. Adding it up. Investing in contraception and maternal and newborn health; 2017. Available from: https://www. guttmacher.org/sites/default/files/factsheet/adding-it-up-contraception -mnh-2017.pdf.

5. Barros AJ, Ronsmans C, Axelson H, et al. Equity in maternal, newborn, and child health interventions in countdown to 2015: a retrospective review of survey data from 54 countries. Lancet. 2012;379(9822):1225-1233. doi:10.1016/S0140-6736(12)60113-5

6 . Ross J. Improved reproductive health equity between the poor and the rich: an analysis of trends in 46 low- and middle-income countries. Glob Health Sci Pract. 2015;3(3):419-445. doi:10.9745/ GHSP-D-15-00124

7. Ali M, Seuc A, Rahimi A, Festin M, Temmerman M. A global research agenda for family planning: results of an exercise for setting research priorities. Bull World Health Organ. 2014;92:93-98. doi:10.2471/BLT.13.122242

8. Murray SF, Hunter BM, Bisht R, Ensor T, Bick D. Effects of demand-side financing on utilisation, experiences, and outcomes of maternity care in low- and middle-income countries: a systematic review. BMC Pregnancy Childbirth. 2014;14:30. doi:10.1186/14712393-14-30

9. Bellows B, Bulaya C, Inambwae S, Lissner CL, Ali M, Bajracharya A. Family planning vouchers in low and middle income countries: a systematic review. Stud Fam Plann. 2016;47(4):357-370. doi:10.1111/sifp.12006

10. Bellows NM, Bellows BW, Warren C. Systematic Review: the use of vouchers for reproductive health services in developing countries: systematic review. Trop Med Int Health. 2011;16(1):84-96. doi:10.1111/j.1365-3156.2010.02667.x

11. Menotti EP, Farrell M. Vouchers: a hot ticket for reaching the poor and other special groups with voluntary family planning services. Glob Health Sci Pract. 2016;4(3):384-393. doi:10.9745/GHSP-D-1600084

12. High Impact Practices in Family Planning (HIPs). Vouchers: addressing inequities in access to contraceptive services; 2015. Washington (DC): United States Agency for International Development. Available from: https://www.fphighimpactpractices.org/resources/ vouchers.

13. Mackay A Increasing access and choice in FP through private sector vouchers in Uganda. Presented at: the international conference on family planning; 2016. Nusa Dua, Indonesia. Available from: https:// www.xcdsystem.com/icfp/program/index.cfm?pgid=288\&search= 1 \&qtype $=$ Session $\&$ sid $=16529 \&$ submit $=$ Go .

14. National Institute of Population Studies (NIPS) [Pakistan] and ICF. Pakistan Demographic and Health Survey 2017-18. Islamabad, Pakistan, and Rockville, Maryland, USA: NIPS and ICF; 2018.

15. Azmat SK, Shaikh BT, Hameed W, et al. Impact of social franchising on contraceptive use when complemented by vouchers: a quasi-experimental study in rural Pakistan. PLoS One. 2013;8(9): e74260. doi:10.1371/journal.pone. 0074260

16. Azmat SK, Hameed W, Mustafa G, et al. Engaging with community-based public and private mid-level providers for promoting the use of modern contraceptive methods in rural Pakistan: results from two innovative birth spacing interventions. Reprod Health. 2015;13:25.

17. Ali M, Azmat SK, Hamza HB, Rahman MM, Hameed W. Are family planning vouchers effective in increasing use, improving equity, and reaching the underserved? An evaluation of a voucher program in Pakistan. BMC Health Serv Res. 2019;19:200. doi:10.1186/s12913019-4027-z 
18. UNICEF. Multiple Indicator Cluster Survey (MICS) Pakistan, 2007. Pakistan

19. Imran B, Fareed A, Tafseer M Factors associated with utilization of maternal health services in Faisalabad District of Punjab, Pakistan. Working paper series no. 7, Greenstar Social Marketing Pakistan; 2013. Available from: https://www.greenstar.org.pk/assets/publica tions/pub8.pdf. Accessed October 1, 2019.

20. Imran B, Fareed A, Tafseer M. A cross sectional study to determine factors associated with utilization of maternal health services in Faisalabad district of Punjab, Pakistan. Pak J Public Health. 2013;3 (1):17-26.

21. Mackenbach JP, Kunst AE. Measuring the magnitude of socioeconomic inequalities in health: an overview of available measures illustrated with two examples from Europe. Soc Sci Med. 1997;44 (6):757-771. doi:10.1016/S0277-9536(96)00073-1

22. World Health Organization. Handbook on Health Inequality Monitoring with a Special Focus on Low-And Middle-Income Countries. Geneva: World Health Organization; 2013.

23. Kakwani N, Wagstaff A, Van Doorslaer E. Socioeconomic inequalities in health: measurement, computation, and statistical inference. J Econom. 1997;77(1):87-103. doi:10.1016/S0304-4076(96)01807-6

24. Boddam-Whetham L, Gul X, Al-Kobati E, Gorter AC. Vouchers in fragile states: reducing barriers to long-acting reversible contraception in Yemen and Pakistan. Glob Health Sci Pract. 2016;4(Suppl 2): S94-S108. doi:10.9745/GHSP-D-15-00308
25. Asadi-Lari M, Packham C, Gray D. Need for redefining needs. Health Qual Life Outcomes. 2003;1:34-38. doi:10.1186/1477-75251-34

26. Culyer AJ. Equity - some theory and its policy implications. $J$ Med Ethics. 2001;27:275-283. doi:10.1136/jme.27.4.275

27. High-Impact Practices in Family Planning (HIP). Family planning and immunization integration: reaching postpartum women with family planning services. Washington, DC: USAID; 2013. Available from: http://www.fphighimpactpractices.org/briefs/family-planningand-immunization-integration.

28. Gorter AC, Ir P, Meessen B Evidence review: results-based financing of maternal and newborn health care in low- and lower-middleincome countries. German Federal Ministry for Economic Cooperation and Development (BMZ) through the sector project PROFILE at GIZ - Deutsche Gesellschaft für Internationale Zusammenarbeit; 2013. Available from: http://www.oecd.org/dac/ peer-reviews/Evidence-RBF-maternal-health.pdf.

29. Brody CM, Bellows N, Campbell M, Potts M. The impact of vouchers on the use and quality of health care in developing countries: a systematic review. Glob Public Health. 2013;8(4):363-388. doi:10.1080/17441692.2012.759254
Journal of Multidisciplinary Healthcare

\section{Publish your work in this journal}

The Journal of Multidisciplinary Healthcare is an international, peerreviewed open-access journal that aims to represent and publish research in healthcare areas delivered by practitioners of different disciplines. This includes studies and reviews conducted by multidisciplinary teams as well as research which evaluates the results or conduct of such teams or healthcare processes in general. The journal

\section{Dovepress}

covers a very wide range of areas and welcomes submissions from practitioners at all levels, from all over the world. The manuscript management system is completely online and includes a very quick and fair peer-review system. Visit http://www.dovepress.com/testimonials. php to read real quotes from published authors. 